\title{
Genome Analysis of Phage SMSAP5 as Candidate of Biocontrol for Staphylococcus aureus
}

\author{
Young-Duck Lee ${ }^{1}$ and Jong-Hyun Park* \\ Department of Food Science and Biotechnology, Gachon University, Sungnam 461-701, Korea \\ ${ }^{1}$ Department of Food Science and Engineering, Seowon University, Cheongju 361-742, Korea
}

\begin{abstract}
In this study, we reported the morphogenetic analysis and genome sequence by genomic analysis of the newly isolated staphylococcal phage SMSAP5 from soil of slaughterhouses for cattle. Based on transmission electron microscopy evident morphology, phage SMSAP5 belonged to the Siphoviridae family. Phage SMSAP5 had a double-stranded DNA genome with a length of $45,552 \mathrm{bp}$ and $33 \% \mathrm{G}+\mathrm{C}$ content. Bioinformatics analysis of the phage genome revealed 43 open reading frames. A blastn search revealed that its nucleotide sequence shared a high degree of similarity with that of the Staphylococcus phage tp310-2. In conclusion, this study is the first report to show the morphological features and the complete genome sequence of the phage SMSAP5 from soil of slaughterhouses for cattle.
\end{abstract}

Key words: $S$. aureus, phage, genome, slaughterhouse

\section{Introduction}

Staphylococcus aureus among the food-borne pathogens is recognized worldwide as the important bacteria due to a combination of toxin mediated virulence, invasiveness and antibiotics resistance (Chambers, 2001). The primary reservoir is on the skin and mucous membranes of animals (Jaglic et al., 2010; van Duijkeren et al., 2004), and also $S$. aureus is the main etiological agent of bovine mastitis (Fessler et al., 2010). Slaughter is a process with many risks for contamination of the cattle carcass with potentially $S$. aureus. $S$. aureus can be used as an indicator of the general hygiene, including the hygienic status of the soil, water and equipment in the slaughterhouse (Borch et al., 1996).

Staphylococcal food-borne diseases resulting from consumption of contaminated food are the second common cause among reported foodborne illnesses in US (Altekruse et al., 1997; Bunning et al., 1997; Holmberg and Blake, 1984; Levine et al., 1991). The estimated \$50 million is spent each year for managing $S$. aureus poisoning

*Corresponding author: Jong-Hyun Park, Department of Food Science and Biotechnology, Gachon University, Seongnam 461-701, Korea. Tel: +82-31-750-5523, Fax: +82-31-750-5501, E-mail: p5062@gachon.ac.kr in hospitals, and the costs to the dairy industry are even higher in Canada (Bradley and Teresa, 2005; Kim, 2001). The cases reported have been around 1600 in France between 1999 and 2000 (Le Loir et al., 2003). According to a report from MFDS (Ministry of Food and Drug Safety in Korea), $S$. aureus poisoning has increased from 363 patients in 2001 to 863 patients in 2005 in domestic (MFDS, 2005).

S. aureus produces various virulence factors, which are staphylococcal enterotoxin and toxic shock syndrome toxin I inducing superantigenic activity (Hennekinne et al., 2012). Especially, phage-encoded virulence factors provide $S$. aureus with various toxins such as staphylococcal enterotoxin A (SEA), staphylococcal enterotoxin E (SEE), exfoliative toxin A, and Panton-Valentine leukocidin (Pinchuk et al., 2010). Through bioinformatics analysis and molecular characteristics, the relationships between staphylococcal phages and $S$. aureus in antibiotic resistance, gene transfer, pathogenesis, and evolution have been recently discussed (Skippington and Ragan, 2011). Also, staphylococcal phages have been intensively studied and have been used in a variety of practical applications such as phage therapy (Sulakvelidze et al., 2001), the detection and biocontrol of foodborne pathogens (Dinnes et al., 2007; Greer, 2005; Hudson et al., 2005), and bioremediation (Withey et al., 2005). More recently, phages 
have been exploited in an attempt to remove bacterial biofilms (Lu and Collins, 2007). In application of phage for $S$. aureus, phages are effective against $S$. aureus in contaminated foods or food-stuffs (Choi, 2009; Manoharadas; 2009; O'Flaherty et al., 2005; Rodriguez, 2010), and phages active against $S$. aureus have been widely studied in experimental infections in animals (Capparelli et al., 2007; García et al., 2009; Matsuzaki et al., 2003; Wills et al., 2005). In this study, we reported the morphogenetic analysis and genome sequence analysis of phage SMSAP5 for $S$. aureus isolated from soil of slaughterhouses for cattle.

\section{Materials and Methods}

\section{Isolation of phage for $\boldsymbol{S}$. aureus}

To isolate the phage for $S$. aureus, soil samples collected from the Icheon slaughterhouse in Korea. Host strain of phage was $S$. aureus ATCC25923. This strain was grown in Luria-Bertani (LB) broth or agar supplemented with $10 \mathrm{mM} \mathrm{CaCl}_{2}(\mathrm{LBC})$ at $37^{\circ} \mathrm{C}$ overnight in a shaking incubator. To isolate phage for $S$. aureus, soil samples were analyzed by a plaque assay. Briefly, $5 \mathrm{~g}$ soil sample was mixed with 7-8 Log CFU/mL of $S$. aureus and incubated with shaking at $37^{\circ} \mathrm{C}$ for $24 \mathrm{~h}$. Then, the culture was centrifuged, and the supernatant was filtered by 0.22 $\mu \mathrm{m}$ syringe membrane filter. The filtrate was tes- ted for phage by plaque assay using double overlay agar. The plaque was picked, phages eluted with SM buffer $[100 \mathrm{mM}$ $\mathrm{NaCl}, 8 \mathrm{mM} \mathrm{MgSO} \cdot \cdot 7 \mathrm{H}_{2} \mathrm{O}, 50 \mathrm{mM}$ Tris- $\left.\mathrm{Cl}(\mathrm{pH} 7.5)\right]$, and re-picked. Phage was propagated and purified by method of Sambrook (Sambrook and Russel, 2001).

\section{Morphology and phage DNA extraction}

To confirm the morphological characteristics, purified phage particles were negatively stained with $2 \%$ aqueous uranyl acetate $(\mathrm{pH} 4.5)$ on a carbon-coated grid and examined by transmission electron microscopy. Phage DNA was collected from polyethylene glycol precipitated phage particles by method of Manfioletti et al. (Manfioletti and Schneider, 1988) with some modifications. DNase I (10 $\mu \mathrm{g} / \mathrm{mL})$ and RNase A $(20 \mu \mathrm{g} / \mathrm{mL})$ were added to phage lysate, respectively. After incubation at room temperature for $15 \mathrm{~min}, 0.5 \mathrm{M}$ EDTA ( $\mathrm{pH} \mathrm{8.0)}$ ) and proteinase $\mathrm{K}$ (1 $\mathrm{mg} / \mathrm{mL}$ ) were added, followed by incubation at $65^{\circ} \mathrm{C}$ for $30 \mathrm{~min}$. After incubation, the nucleic acid was extracted with a mixture of phenol-chloroform-isoamyl alcohol $(25: 24: 1)$. The nucleic acid was precipitated with ethanol, and resuspended in sterile distilled water. Phage DNA was stored at $-80^{\circ} \mathrm{C}$.

\section{Genome sequence analysis}

The genome sequence was generated by ultra-high throughput GS FLX sequencing to 20-fold redundancy on average. The nucleotide sequences were compared with those of other genes in GenBank by the BLAST program (http://www.ncbi.nlm.nih.gov/BLAST/). The open reading frames (ORFs) were identified with the ORF Finder at the National Center for Biotechnology Information site (http://www.ncbi.nlm.nih.gov/gorf.html). The molecular weight and isoelectric point were calculated with the Compute $\mathrm{pI} / \mathrm{Mw}$ program (http://www.expasy.ch/tools/pi _tool.html). The promoter and tRNA were identified with promoter hunter (http://www.phisite.org) and tRNAscanSE program (http://lowelab.ucsc.edu/tRNAscan-SE/), respectively.

\section{Nucleotide sequence accession number}

The complete genome sequence of phage SMSAP5 was deposited at GenBank under accession number JQ779023.

\section{Results and Discussion}

Phage SMSAP5 was isolated and purified from soil of slaughterhouse by a plaque assay. To confirm morphology, phage SMSAP5 was confirmed by transmission electron microscopy (Fig. 1). According to morphological analysis, Phage SMSAP5 had long, non-contractile tails and icosahedral heads belonging to the Siphoviridae fam-

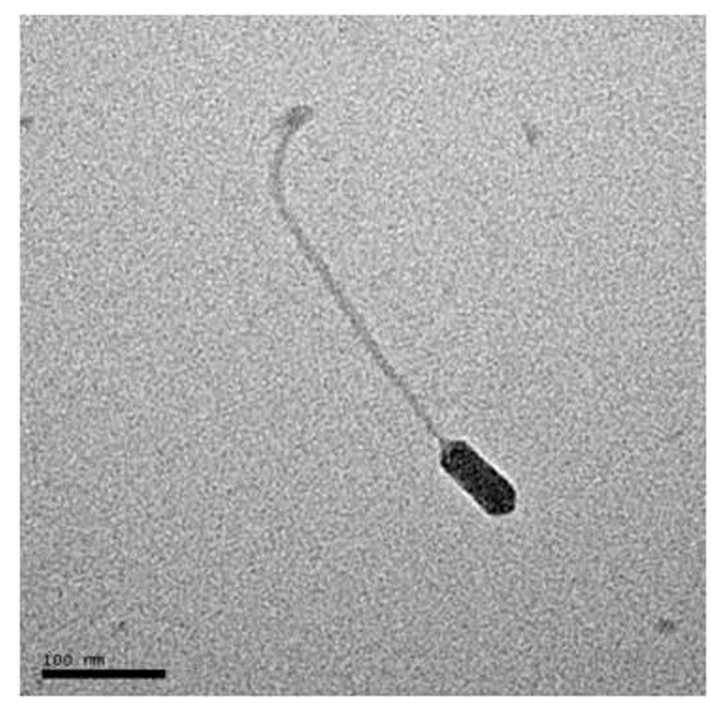

Fig. 1. Transmission electron micrograph showing morphology of phage SMSAP5. The scale bar in the lower right corner represents $100 \mathrm{~nm}$. 
ily in the order Caudovirales. Phages can be tailed, polyhedral, filamentous, or pleomorphic, and most of them contain double-stranded DNA. About 5,568 bacterial viruses have been examined by electron microscopy. At least $5,360(96.2 \%)$ of these are tailed bacteriophages known as Caudovirales (Ackermann, 2007). The length of phage SMSAP5 genome was 45,552 bp with $33 \% \mathrm{G}+\mathrm{C}$ contents. As the results of genome sequence were searched by blastn, the Phage SMSAP5 sequence shared a high nucleotide similarity (89\%) with the bacteriophage tp3102 (accession number: EF462198). Bioinformatic analysis of the phage SMSAP5 genome revealed 43 putative ORFs. A total of 28 ORFs were similar to gene in the GenBank with annotated function. In accordance with comparison of phage SMSAP5 sequences were attributed to composition of basic functional modules, as follows; replication, DNA packaging, morphogenesis, lysis, and lysogeny (Fig. 2).

In the structure/morphogenesis module, the predicted protein encoded by ORF28 was identified as the minor structural protein and showed similarity to the tail fiber protein of Staphylococcus phage phiSauS-IPLA35. This protein was found to play the most important role in host specificity and adsorption of phage to the outer membrane of a bacterial cell (Wood et al., 1978). ORF31 protein was the longest predicted ORF of phage SMSAP5 genome and showed similarities to the tape measure protein repeat from S. aureus subsp. aureus MRSA131. Tape measure protein determined tail length by working as a template for measuring length during tail assembly (Katsura and Hendrix, 1984). ORF34 and ORF35 encoded the products homologous to the putative minor tail protein by $100 \%$ identity. The protein encoded by ORF39 showed $100 \%$ identity to the putative capsid protein of Staphylococcus phage phi2958PVL. Other structural/morphogenesis-related proteins were those encoded by ORF30 and ORF40. Within the DNA-packaging cluster, the protein encoded by ORF42 and ORF43 was identified as a terminase large subunit and a terminase small subunit, respectively. Moreover, the protein encoded by ORF41 showed
$100 \%$ similarity to the phage portal protein of Staphylococcus phage phi 12 . The protein encoded by ORF23 in the lysogenic region was identified as a site-specific recombinase (accession number: EGS98875).

In the replication modules, ORF1 showed $100 \%$ identity to $\mathrm{HNH}$ endonuclease of $S$. aureus A9754. HNH endonucleases are small DNA binding and digestion proteins characterized by two His residues and an Asn residue (Moodley et al., 2012). ORF2, ORF18, and ORF32 were identified as phage regulatory proteins. ORF3 encoded a protein homologous with helicase from Staphylococcus aureus subsp. aureus EMRSA16 with 100\% identity. ORF7 showed $97 \%$ identity to dUTP diphosphatase superfamily protein of $S$. aureus subsp. aureus ATCC BAA-39. ORF8 encoded a protein $91 \%$ similar in identity to acetyltransferase family protein from $S$. aureus subsp. aureus CIGC348. The putative protein of ORF11 matched a putative DNA-binding protein from Staphylococcus phage phi2958PVL. ORF12 showed $99 \%$ similarity with DNA polymerase from $S$. aureus A6224. ORF22 encoded protein homologous with the $\mathrm{Na} / \mathrm{K}$ ATPase from Staphylococcus phage phi 12 with $100 \%$ identity.

In the module for lysis, ORF24 encoded a protein identical nearly to the $N$-acetylmuramoyl ${ }_{\mathrm{L}}$-alanine amidase from $S$. aureus subsp. aureus COL, and ORF25 encoded the same protein with the holin from Staphylococcus phage phiSLT. The function of holin might be to create a lesion in the cytoplasmic membrane through which endolysin passed (Young, 1992). The putative protein of ORF29 was identified as a endopeptidase tail family protein. This family is of prophage tail proteins that are probably acting as endopeptidases. Finally, the predicted protein of ORF4 showed similarity to the virulence-associated protein E from $S$. aureus subsp. aureus USA300 FPR3757 with $100 \%$ identity.

In conclusion, we analyzed morphological property and genome sequence of phage SMSAP5 isolated from soil of slaughterhouses for cattle. Newly isolated phage SMSAP5 for $S$. aureus was slightly different to genome sequence of any other phages of the members of $S$. aureus. Lately,

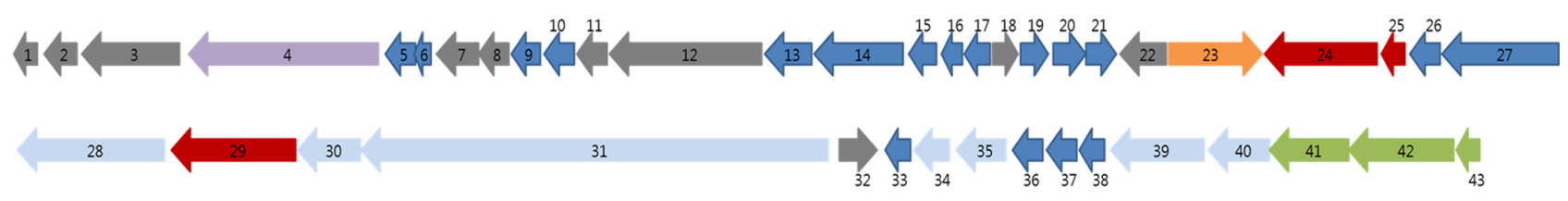

Fig. 2. Schematic representation of the dsDNA genome of the phage SMSAP5. Putative ORFs are presented as arrows, with predicted functions where available. Proposed modules are based on predicted functions. Grey, replication; purple, virulence; orange, lysogeny; red, lysis; pale blue, morphogenesis; green, DNA packaging. 
phages have been intensively studied, and have been used for a variety of practical applications, such as a phage therapy, the biocontrol of food-borne pathogens, and the detection of pathogenic bacteria-like phage-typing. Therefore, phage SMSAP5 should be studied more for biocontrol of $S$. aureus in livestock industry such as dairy and meat processing industries.

\section{Acknowledgements}

This work was supported by a National Research Foundation (NRF) grant funded by the South Korean government (20110012221).

\section{References}

1. Ackermann, H. W. (2007) 5500 Phages examined in the electron microscope. Arch. Virol. 152, 227-243.

2. Altekruse, S. F., Cohen, M. L., and Swerdlow, D. L. (1997) Emerging food borne disease. Emerg. Infect. Dis. 3, 285-293.

3. Bradley, G. S., and Teresa, K. (2005) Staphylococcal enterotoxins: A purging experience in review, Part I. Clin. Microbiol. Newsletter. 27, 179-186.

4. Bunning, V. K., Lindsay, J. A., and Archer, D. L. (1997) Chronic health effects of microbial foodborne disease. World Health Stat. 50, 51-56.

5. Borch, E., Nesbakken, T., and Christensen, H. (1996) Hazard indentification in swine slaughter with respect to foodborne bacteria. Int. J. Food. Microbiol. 30, 9-25.

6. Capparelli, R., Parlato, M., Borriello, G., Salvatore, P., and Iannelli, D. (2007) Experimental phage therapy against Staphylococcus aureus in mice. Antimicrob. Agents Chemother. 51, 2765-2773.

7. Chambers, H. F. (2001) The changing epidemiology of Staphylococcus aureus? Emerg. Infect. Dis. 7, 178-182.

8. Choi, Y. J. (2009) Antibacterial and biofilm removal activity of a podoviridae Staphylococcus aureus bacteriophage SAP2 and a derived recombinant cell-wall-degrading enzyme. Appl. Microbiol. Biotechnol. 86, 1439-1449.

9. Dinnes, J., Deeks, J., Kunst, H., Gibson, A., Cummins, E., and Waugh, N. (2007) A systematic review of rapid diagnostic tests for the detection of tuberculosis infection. Health Technol. Assess. 11, 1-196.

10. Fessler, A. T., Billerbeck, C., Kadlec, K. and Schwarz, S. (2010) Identification and characterization of methicillin-resistant coagulase-negative staphylococci from bovine mastitis. J. Antimicrob. Chemother. 65, 1576-1582.

11. García, P., Madera, C., Martínez, B., Rodríguez, A., and Evaristo Suárez, J. (2009) Prevalence of bacteriophages infecting Staphylococcus aureus in dairy samples and their potential as biocontrol agents. J. Dairy Sci. 92, 3019-3026.

12. Greer, G. G. (2005) Bacteriophage control of foodborne bacteria. J. Food Prot. 68, 1102-1111.

13. Hennekinne, J. A., De Buyser, M. L., and Dragacci, S. (2012)
Staphylococcus aureus and its food poisoning toxins: Characterization and outbreak investigation. FEMS Microbiol. Rev. 36, 815-836.

14. Holmberg, S. D. and Blake, P. A. (1984) Staphylococcal food poisoning in the United States. New facts and old misconceptions. JAMA. 251, 487-489.

15. Hudson, J. A., Billington, C., Carey-Smith, G., and Greening, G. (2005) Bacteriophages as biocontrol agents in food. J. Food Prot. 68, 426-437.

16. Jaglic, Z., Michu, E., Holasova, M., Vlkova, H., Babak, V., Kolar, M., Bardon, J., and Schlegelova, J. (2010) Epidemiology and characterization of Staphylococcus epidermidis isolates from humans, raw bovine milk and a dairy plant. Epidemiol. Infect. 138, 772-782.

17. Katsura, I. and Hendrix, R. W. (1984) Length determination in bacteriophage lambda tails. Cell. 39, 691-698.

18. MFDS (Ministry of Food and Drug Safety). (2005) Foodborne disease management. Available at: http://www.mfds. go.kr/e-stat. Accessed on Nov. 3, 2014.

19. Kim, T. (2001) The economic impact of methicillin-resistant Staphylococcus aureus in Canadian hospitals. Infect. Cont. Hosp. Epidemiol. 22, 99-104.

20. Le Loir, Y., Baron, F., and Gautier, M. (2003) Staphylococcus aureus and food poisoning. Genet. Mol. Res. 31, 63-76.

21. Levine, W. C., Smart, J. F., Archer, D. L., Bean, N. H., and Tauxe, R. V. (1991) Foodborne disease outbreaks in nursing homes, 1975 through 1987. JAMA. 16, 2105-2109.

22. Lu, T. K. and Collins, J. J. (2007) Dispersing biofilms with engineered enzymatic bacteriophage. Proc. Natl. Acad. Sci. USA 104, 11197-11202.

23. Manfioletti, G. and Schneider, C. (1988) A new and fast method for preparing high quality lambda DNA suitable for sequencing. Nucleic Acids Res. 16, 2873-2884.

24. Manoharadas, S., Witte, A., and Bläsi, U. (2009) Antimicrobial activity of a chimeric enzybiotic towards Staphylococcus aureus. J. Biotechnol. 139,118-123.

25. Matsuzaki, S. Yasuda, M., Nishikawa, H., Kuroda, M., Ujihara, T. Shuin, T., Shen, Y., Jin, Z., Fujimoto, S., and Nasimuzzan, M.D. (2003) Experimental protection of mice against lethal Staphylococcus aureus infection by novel bacteriophage ФMR11. J. Infect. Dis. 187, 613-624.

26. Moodley, S., Maxwell, K. L., and Kanelis, V. (2012) The protein gp74 from the bacteriophage HK97 functions as a HNH endonuclease. Protein Sci. 21, 809-818.

27. O'Flaherty, S., Coffey, A., Meaney, W., Fitzgerald, G. F., and Ross, R. P. (2005) The recombinant phage lysin LysK has a broad spectrum of lytic activity against clinically relevant staphylococci, including methicillin-resistant Staphylococcus aureus. J. Bacteriol. 187, 7161-7164.

28. Pinchuk, I. V., Beswick, E. J., and Reyes, V. E. (2010) Staphylococcal enterotoxins. Toxins. 2, 2177-2197.

29. Rodriguez, A. (2010) Use of logistic regression for prediction of the fate of Staphylococcus aureus in pasteurized milk in the presence of two lytic phages. Appl. Environ. Microbiol. 76, 6038-6046.

30. Sambrook, J. and Russel, D. W. (2001) Molecular cloning: a 
laboratory manual. Cold Spring Harbor Laboratory Press, New York.

31. Skippington, E. and Ragan, M. A. (2011) Lateral genetic transfer and the construction of genetic exchange communities. FEMS Microbiol. Rev. 35, 707-735.

32. Sulakvelidze, A., Alavidze, Z., and Morris, J. G. (2001) Bacteriophage therapy. Antimicrob. Agents Chemother. 45, 649659.

33. van Duijkeren, E., Box, A. T., Heck, M. E., Wannet, W. J., and Fluit, A. C. (2004) Methicillin-resistant staphylococci isolated from animals. Vet. Microbiol., 103, 91-97.

34. Withey, S., Cartmell, E., Avery, L. M., and Stephenson, T.
(2005) Bacteriophages - potential for application in wastewater treatment processes. Sci. Total Environ. 339, 1-18.

35. Wills, Q. F., Kerrigan, C., and Soothill, J. S. (2005) Experimental bacteriophage protection against Staphylococcus aureus abscesses in a rabbit model. Antimicrob. Agents Chemother. 49, 1220-1221.

36. Wood, W. B., Conley, M. P., Lyle, H. L., and Dickson, R. C. (1978) Attachment of tail fibers in bacteriophage T4 assembly. J. Biol. Chem. 253, 2437-2445.

37. Young, R. (1992) Bacteriophage lysis: mechanism and regulation. Microbiol. Rev. 56, 430-481.

(Received 2014.11.6/Revised 2014.12.15/Accepted 2014.12.16) 